\title{
IL-23-induced macrophage polarization and its pathological roles in mice with imiquimod-induced psoriasis
}

\author{
Yuzhu Hou ${ }^{1}$, Linnan Zhu ${ }^{1}$, Hongling Tian ${ }^{1}$, Hai-Xi Sun ${ }^{1}$, Ruoyu Wang ${ }^{2 \bowtie}$, Lianfeng Zhang ${ }^{3 \bowtie}$, Yong Zhao ${ }^{1 \bowtie}$ \\ ${ }^{1}$ State Key Laboratory of Membrane Biology, Institute of Zoology, Chinese Academy of Sciences, University of Chinese \\ Academy of Sciences, Beijing 100101, China \\ 2 Department of Oncology, The Affiliated Zhongshan Hospital of Dalian University, Dalian 116001, China \\ ${ }^{3}$ Key Laboratory of Human Diseases Comparative Medicine, Ministry of Health, Institute of Laboratory Animal Science, \\ Chinese Academy of Medical Sciences and Peking Union Medical College, Beijing 100021, China \\ $凶$ Correspondence: wry1963@sohu.com (R. Wang), zhanglf@cnilas.org (L. Zhang), zhaoy@ioz.ac.cn (Y. Zhao)
}

Received September 16, 2017 Accepted December 12, 2017

\begin{abstract}
Macrophages acquire distinct phenotypes during tissue stress and inflammatory responses. Macrophages are roughly categorized into two different subsets named inflammatory M1 and anti-inflammatory M2 macrophages. We herein identified a unique pathogenic macrophage subpopulation driven by IL-23 with a distinct gene expression profile including defined types of cytokines. The freshly isolated resting mouse peritoneal macrophages were stimulated with different cytokines in vitro, the expression of cytokines and chemokines were detected by microarray, real-time PCR, ELISA and multiple colors flow cytometry. Adoptive transfer of macrophages and imiquimod-induced psoriasis mice were used. In contrast to M1- and M2-polarized macrophages, IL-23-treated macrophages produce large amounts of IL-17A, IL-22 and IFN-y. Biochemical and molecular studies showed that IL-23 induces IL-17A expression in macrophages through the signal transducer and activator of transcription 3 (STAT3)-retinoid related orphan receptor-Y T (RORYT) pathway. T-bet mediates the IFN- $Y$ production in IL-23-treated macrophages. Importantly, IL-23-treated macrophages significantly promote the dermatitis pathogenesis in a
\end{abstract}

Yuzhu Hou, Linnan Zhu and Hongling Tian contributed equally to this work as co-first authors.

Electronic supplementary material The online version of this article (https://doi.org/10.1007/s13238-018-0505-z) contains supplementary material, which is available to authorized users. psoriasis-like mouse model. IL-23-treated resting macrophages express a distinctive gene expression prolife compared with M1 and M2 macrophages. The identification of IL-23-induced macrophage polarization may help us to understand the contribution of macrophage subpopulation in Th17-cytokines-related pathogenesis.

KEYWORDS interferon-gamma, interleukin-17, interleukin-23, imiquimod-induced psoriasis, macrophage polarization

\section{INTRODUCTION}

Macrophages demonstrate significant plasticity and are able to modify their phenotype and function in response to the surrounding microenvironments (Murray and Wynn, 2011). It is well known that macrophage polarization display tremendous heterogeneity and is involved in tissue remodeling and pathogenesis. Recently, an elegant study evaluated the transcriptome of human macrophages induced by a variety of stimuli and revealed an extraordinary spectrum of macrophage activation states that far extend the current M1 versus M2-polarization model (Xue et al., 2014). Importantly, the diverse macrophage subsets can have drastic effects on health and disease within the tissues where they reside (Labonte et al., 2014).

IL-23, one member of the IL-12 cytokine family, is crucial in the pathogenesis of psoriasis, experimental autoimmune encephalomyelitis (EAE), collagen-induced arthritis (CIA), inflammatory bowel disease (IBD) (Tonel et al., 2010; Teng et al., 2015) and leukocyte adhesion deficiency type 1 
(LAD1) (Moutsopoulos et al., 2017). Polymorphisms in the gene encoding the IL-23 receptor (IL-23R) are important susceptibility factors for Behcet's disease, ankylosing spondylitis, and IBDs like Crohn's disease and ulcerative colitis (Remmers et al., 2010; Kadi et al., 2013). It is known that IL-23 is essential for the terminal differentiation of IL-17producing T effector cells (Park et al., 2005; McGeachy et al., 2009), which were initially shown to be a chief pathogenic cell population in EAE and CIA (Duerr et al., 2006; Remmers et al., 2010), human psoriasis (Wilson et al., 2007; Lubberts, 2015) and LAD1 (Moutsopoulos et al., 2017). However, in addition to acting on Th17 cells, IL-23 also regulates the function of innate lymphocytes (Guo et al., 2012). IL-23R is predominantly found on activated memory $T$ cells, natural killer (NK) cells, and innate lymphoid cells (ILCs), and at lower levels on monocytes, macrophages, and dendritic cells (DCs) in humans; whereas mouse IL-23R is expressed on activated T cells, ILCs, $ү \delta$ T cells, macrophages and DCs (Kastelein et al., 2007; Awasthi et al., 2009; Aychek et al., 2015). Importantly, studies have demonstrated that IL-23 induces these innate cells to secrete IL-17 and/or IL-22, although it remains unknown whether IL-23 affects the functional development of IL-23R-expressing innate cells in vivo (Cella et al., 2009; Guo et al., 2012; Paget et al., 2012).

We herein demonstrate that IL-23-treated monocyte/macrophages selectively produce IL-17A, IL-22 and IFN-y, and display a distinct lineage gene expression profile in sharply contrast to M1 and M2 subsets. Importantly, M(IL23) macrophages significantly promote the severity of dermatitis pathogenesis in a mouse psoriasis-like model. Thus, our findings reveal a previously unappreciated macrophage polarization driven by IL-23 with unique cell surface markers and cytokine-producing gene profile.

\section{RESULTS}

\section{IL-23 induces a distinct macrophage gene expression profile}

To explore the roles of different cytokines on the expression of IL-17 family members include IL-17A, IL-17B, IL-17C, IL17D, IL-17E (also called IL-25) and IL-17F in macrophages, we firstly detected the expression of these genes in freshly isolated mouse peritoneal resident macrophages after different cytokines and LPS stimulation for $48 \mathrm{~h}$ by real-time PCR. Among the 15 cytokines and LPS studied, only IL-23 significantly promoted IL-17A and IL-17F expression, while resting macrophages expressed almost undetectable levels of IL-17A and IL-17F ( $P<0.001$, Fig. 1A). In addition, IL-23 also significantly induced IL-22 and IFN- $\gamma$ expression in a specific manner compared to other cytokines and LPS stimulation $(P<0.001$, Fig. 1A). IL-23 induced the mRNA and protein expression of Th17-type cytokines in dose- and time-dependent manners as determined by real-time PCR and ELISA assays (Figs. 1B, 1C and S1). The expressions of IL-17A and IFN- $\gamma$ in IL-23-treated macrophages were further confirmed by flow cytometry and confocal microscopy

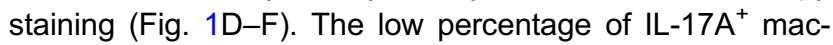
rophages might be due to the limited IL-23R expression on $\mathrm{CD} 11 \mathrm{~b}^{+} \mathrm{F} 4 / 80^{+}$macrophages (Fig. S2). However, IL-23 failed to induce significantly high levels of IL-17C, IL-17D and IL$17 \mathrm{E}$ expression in macrophages (Fig. S3). Furthermore, IL23 significantly induced IL-17A, IL-17F, IL-22 and IFN-Y expression in tissue resident macrophages isolated from spleens, lungs and liver as well (Fig. S4). To exclude the potential contamination of other immune cells like T cells, B cells and ILCs during the differentiation process, we sorted the peritoneal resident cells of naïve mice to obtain highly purified $\mathrm{F} 4 / 80^{+}$cells. It is true that more than $99 \%$ of the sorted cells were CD $11 \mathrm{~b}^{+} \mathrm{F} 4 / 80^{+}$cells and indeed these cells also expressed high levels of IL-17A and IL-17F after IL-23 treatment for $48 \mathrm{~h}$ (Fig. S5). In addition, the in vitro bone marrow-derived macrophages also expressed higher levels of IL-17A, IL-17F, IL-22 and IFN-y after IL-23 stimulation (Fig. S6). Thus, IL-23 promotes IL-17A, IL-17F, IL-22 and IFN-y expression in resting mouse macrophages in a specific manner. However, the IL-23-induced expression of IL-17A, IL-17F, and IL-22 in macrophages were significantly lower than Th17 cells (Fig. S7A), as well as the lower IFN-y expression when comparing with Th1 (Fig. S7B).

To investigate whether IL-23 induces a unique macrophage polarization in contrast to M1 and M2 subpopulations, we compared the expression patterns of the subpopulationrelated marker genes in macrophages treated with LPS + IFN-y, IL-4 and IL-23, respectively. Surprisingly, IL-23 failed to induce either the expression of $M 1$ marker genes like iNOS, TNF- $\alpha, I L-12$ and IL-1 $\beta$, or M2-related genes like Arg1, YM1 and FIZZ1 (Murray and Wynn, 2011), as detected by quantitative PCR, ELISA and bioactivity assays (Fig. 2A-D), whereas IL-23-treated macrophages specifically expressed IL-17A, IL-17F, IL-22 and IFN-Y (Fig. 2A-E). The distinct expression patterns of TNF- $\alpha$, iNOS, IFN-y, IL-17 and IL-22 in $M 1$ and $M(I L-23)$ macrophages were further determined by flow cytometry and confocal assays (Fig. 2F and 2G). To further demonstrate whether $\mathrm{M}(\mathrm{IL}-23)$ macrophages represent a distinct polarization of macrophages, we thus determined the gene expression profiles of $M 1, M 2$ and $M(I L-23)$ cells by microarray analysis. Indeed, M(IL-23) macrophages expressed a unique panel of genes in sharply contrast to M1 and M2 macrophages (Fig. 3A). The microarray data were submitted to the NCBI Gene Expression Omnibus (GEO, http://www. ncbi.nlm.nih.gov/geo, under accession number GSE 102274). M1, M2 and M(IL-23) cells expressed significant different gene profiles with up-regulated 301 genes and downregulated 135 genes specifically in $\mathrm{M}(\mathrm{IL}-23)$ cells compared with $\mathrm{M} 1$ and $\mathrm{M} 2$ cells (Fig. 3B). Interestingly, M1, M2 and M(IL23) cells expressed distinctive gene profiles of cytokines and chemokines, as determined by mRNA microarray and realtime PCR methods (Figs. $3 \mathrm{C}$ and S8). We also found that $\mathrm{M} 1$ macrophages expressed high levels of $\mathrm{I}-\mathrm{A}^{\mathrm{b}}$ and $\mathrm{M} 2$ macrophages expressed high CD206 on the surface as reported 


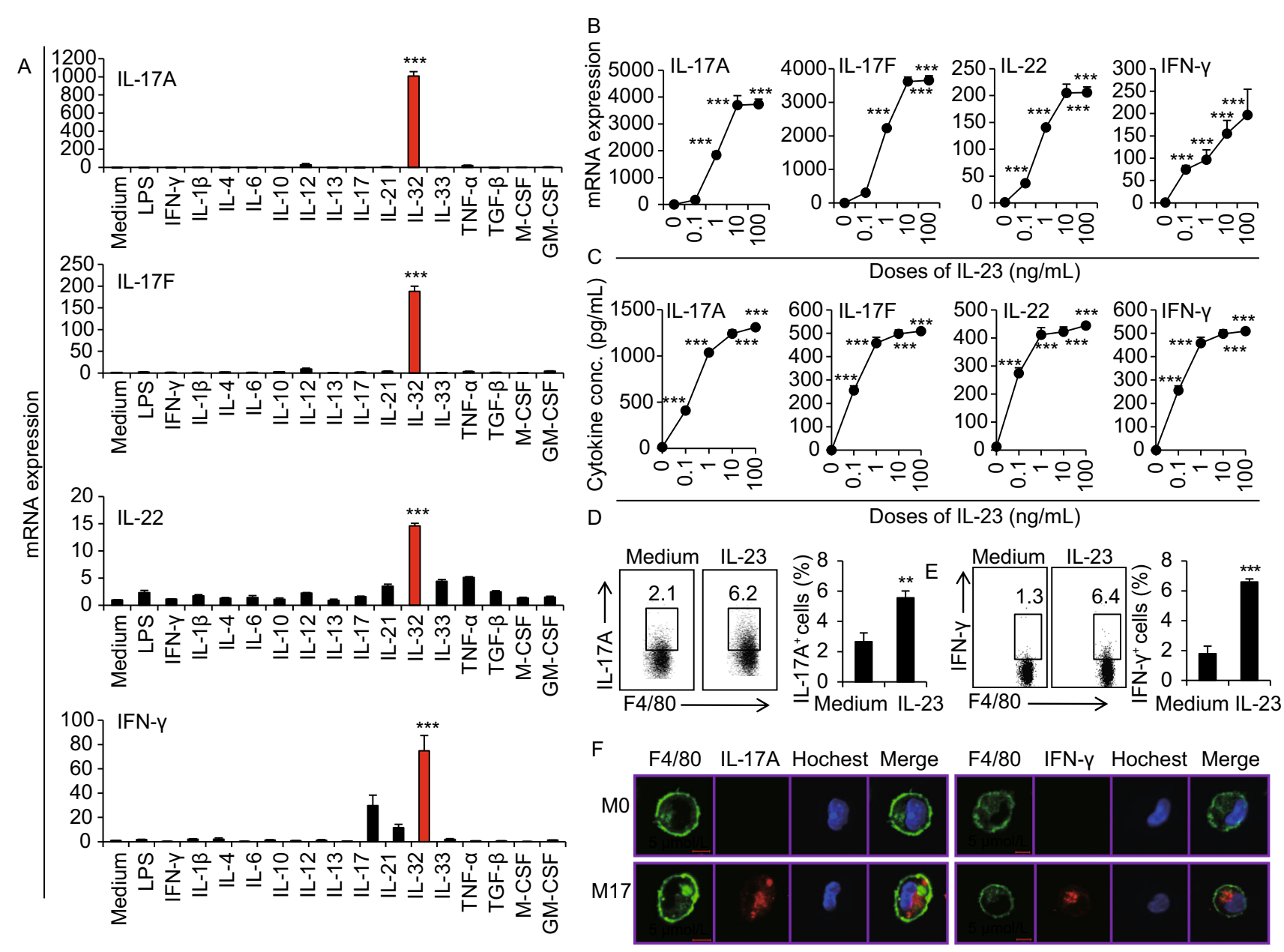

Figure 1. Cytokine expression of macrophages stimulated with different cytokines. (A) The freshly isolated peritoneal macrophages (PEMs) were stimulated with different cytokines and LPS for $48 \mathrm{~h}$. Cytokine mRNA expression were detected by realtime PCR. (B) mRNA expression of IL-17A, IL-17F, IL-22 and IFN-y in PEMs treated with different doses of IL-23. (C) Concentrations of IL-17A, IL-17F, IL-22 and IFN-y in the media of PEMs after IL-23 treatment for $48 \mathrm{~h}$. (D) The percentages of IL-17A ${ }^{+}$cells in F4/80 PEMs were detected by a flow cytometry. $(E)$ The percentages of IFN- $\gamma^{+}$cells in F4/80 PEMs treated with IL-23. (F) The expression of IL-17A and IFN-y in PEMs were determined using two-photon microscope. Data were shown as mean $\pm \operatorname{SD}(n=3)$. ${ }^{\star \star} P<0.01$, ${ }^{* * *} P<0.001$ compared with the control.

previously (Sun et al., 2012), but M(IL-23) macrophages expressed low levels of $\mathrm{I}-\mathrm{A}^{\mathrm{b}}$ and CD206 molecules (Fig. 3D and $3 \mathrm{E}$ ). Thus, IL-23-treated macrophages express different cytokines and cell surface markers as M1 and M2 macrophages.

\section{M(IL-23), M1 and M2 polarizations are reciprocally regulated}

To address whether M(IL-23) macrophages could arise from M1 or M2 cells, we examined the potential differentiation ability into M(IL-23) macrophages from resting M0, M1 and M2 macrophages, respectively. When M1 macrophage polarization was induced from resting macrophages by LPS + IFN-y as reported (Zhu et al., 2014), these M1-polarized macrophages were remarkably resistant to $M(I L-23)$ induction as indicated by the significantly poor IL-17A, IL-17F, IL22 and IFN-y expression when they were subsequently stimulated with IL-23 as determined by real-time PCR and ELISA $(P<0.001$, Fig. 4A and 4B). Identical results were also observed when M1-polarized peritoneal macrophages freshly isolated from TG-pre-treated mice were used instead of the in vitro LPS + IFN- $\gamma$-induced macrophages (Fig. 4C). M2 macrophages induced by IL-4 were hard to respond to the subsequent IL-23 treatment in terms of IL-17A, IL-17F, IL-22 and IFN- $y$ expression ( $P<0.001$, Fig. 4D and 4E). Thus, resting macrophages are susceptible to IL-23-driven $\mathrm{M}(\mathrm{IL}-23)$ polarization but $\mathrm{M} 1$ and $\mathrm{M} 2$ macrophages are highly resistant to trans-differentiation into $M(I L-23)$ macrophages. 


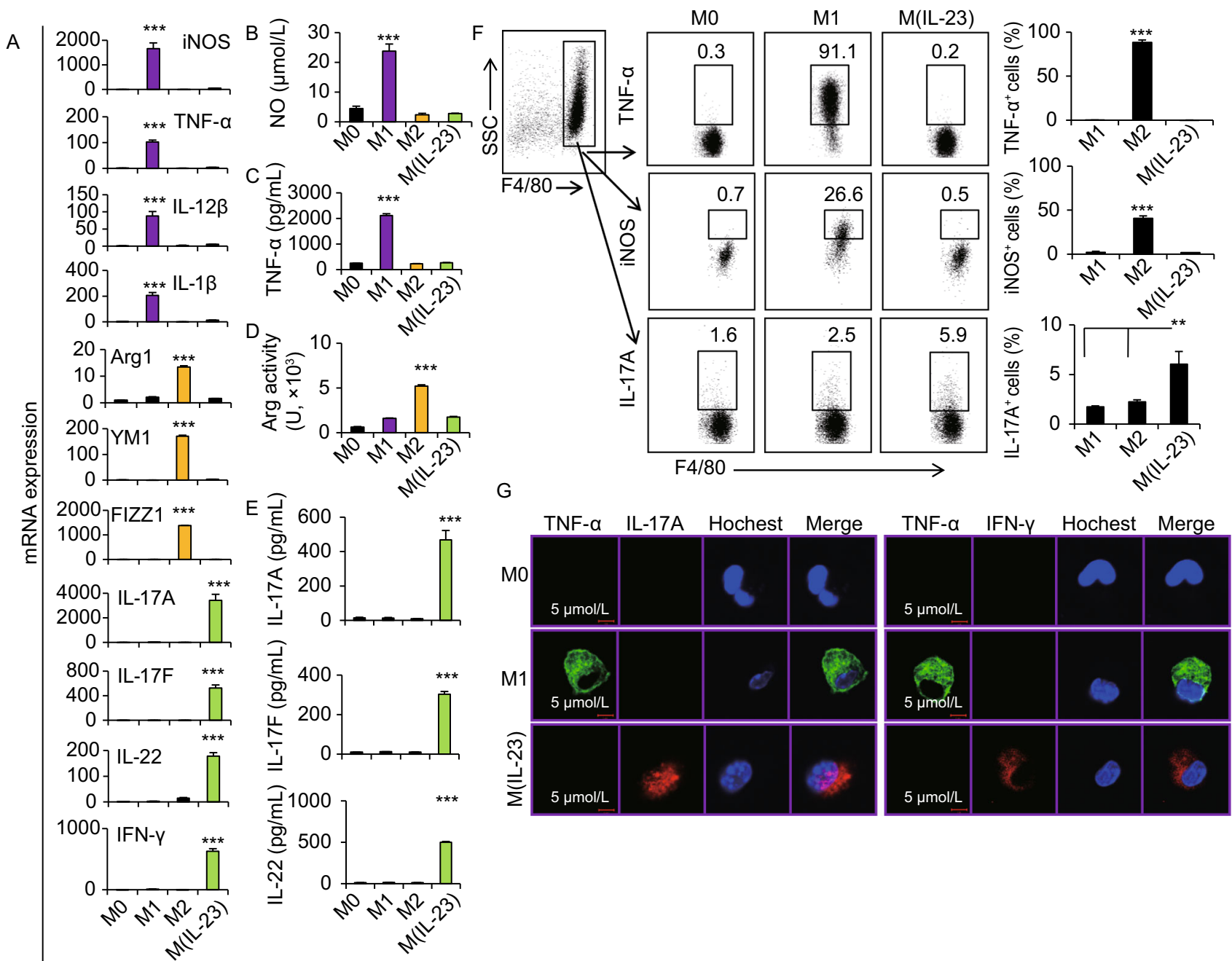

Figure 2. IL-23-treated macrophages produce a distinctive panel of cytokines. (A) The mRNA expression of M1 and M2 marker molecules and Th17-cytokines in macrophages were detected by real-time PCR. (B) NO concentrations in M0, M1, M2 and M(IL-23) macrophage culture medium. (C) TNF- $\alpha$ concentrations in the culture medium. (D) Arginase activity of M0, M1, M2 and M(IL-23) macrophages was assayed. (E) Concentrations of IL-17A, IL-17F and IL-22 in the culture medium. (F) Representative flow cytometry results (left) and summarized percentages (right) of TNF- $\alpha^{+}, \mathrm{iNOS}^{+}$and IL-17A ${ }^{+}$cells in the F4/80 macrophages. (G) The expression of TNF- $\alpha, I L-17 A$ and IFN- $y$ in M0, M1 and M(IL-23) were determined using a two-photon microscope. Data were shown as mean \pm SD $(n=4) .{ }^{* *} P<0.01,{ }^{* *} P<0.001$ compared with the control.

The involvement of STAT3-RORYT and T-bet in M(IL-23) polarization

In order to investigate the signaling pathways activated by IL-23 in macrophages, we performed the pathway analysis based on the gene expression data. As expected, IL-17 and JAK-STAT signaling pathways were activated in macrophages after IL-23 stimulation (Fig. S9A and S9B). Furthermore, IL-23 promoted STAT3 activation in macrophages in terms of the enhanced levels of p-STAT3 (Y705 and S727, Fig. 5A) as previously observed in T-cells (Cho et al., 2006; Teng et al., 2015). Inhibition of STAT3 activation by STAT3specific inhibitor NSC (NSC74859) significantly decreased the IL-17A, IL-17F and IL-22 mRNA and protein expression in M(IL-23) macrophages, while inhibition of STAT3 failed to inhibit IFN- $y$ expression (Figs. 5B and S10A). It is reported that RORYT, RORa, IRF4 and BATF are critical transcription factors for Th17 cell induction (Huber et al., 2008; Chung et al., 2009; Ciofani et al., 2012). The expression of RORYT and RORa were enhanced in M(IL-23) macrophages at both mRNA and protein levels (Fig. 5C and 5D), which was further confirmed by confocol imaging analysis (Fig. S11A and S11B). However, no detectable IRF4 and BATF expression in M(IL-23) macrophages was observed in contrast to Th17 cells, as determined by real-time PCR, Western blots and flow cytometry (Figs. 5C, 5D and S12). Thus, the enhanced expression of RORYT and RORa raised the possibility that 
A

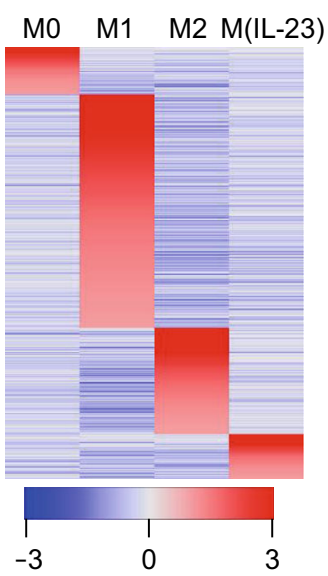

B Up-regulated genes

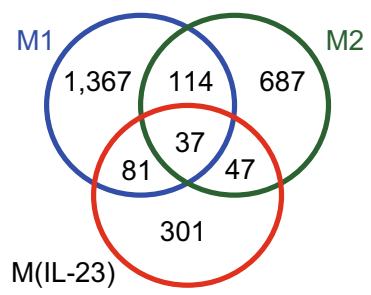

Down-regulated genes

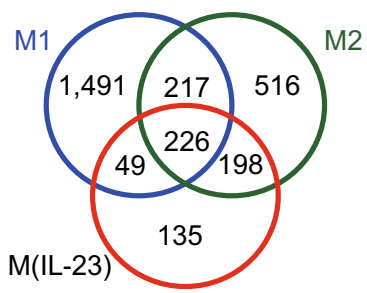

C M0 M1 M2 M(IL-23)
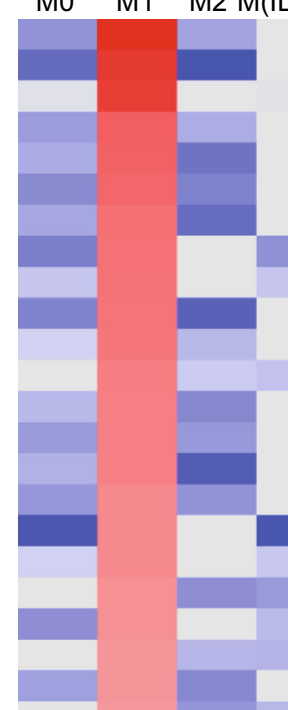

Cxcl9

Cxcl10

Cxcl11

II1 $\alpha$

Tnf

116

$\mathrm{Ccl} 5$

$\mathrm{Ccl} 2$

II1f9

Csf3

Tnfsf10

II1f6

$\mathrm{Ccl} 4$

$\mathrm{Cxcl} 2$

II1b

Cxcl1

Ccl7

II27

II10

$\mathrm{CxCl} 3$

Tnfsf15

$\mathrm{Ccl} 3$

II11

II17a

II17f

II22

Ifng

Tnfsf11

Tnfsf14

Cxcl13

$\mathrm{Ccl} 24$

$\mathrm{Ccl} 8$

$\mathrm{Ccl} 12$

Ccl9

Cxcl12

Ccl6

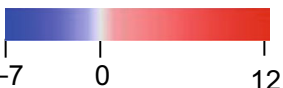

D

M0
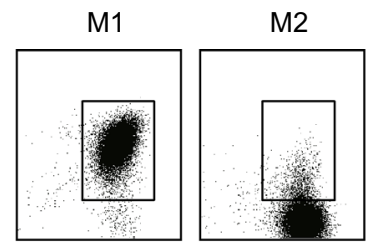

$\mathrm{M}(\mathrm{IL}-23)$
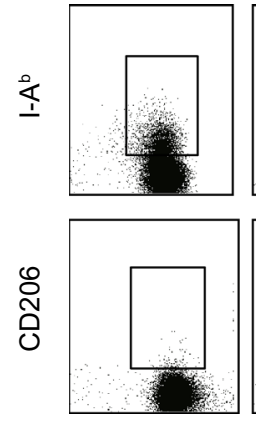

$\mathrm{F} 4 / 80$
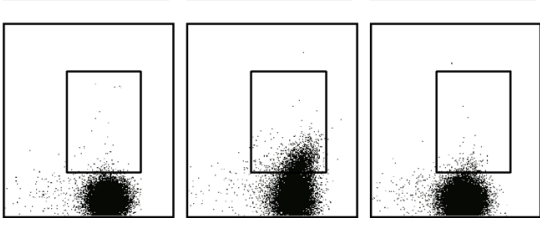

$E$
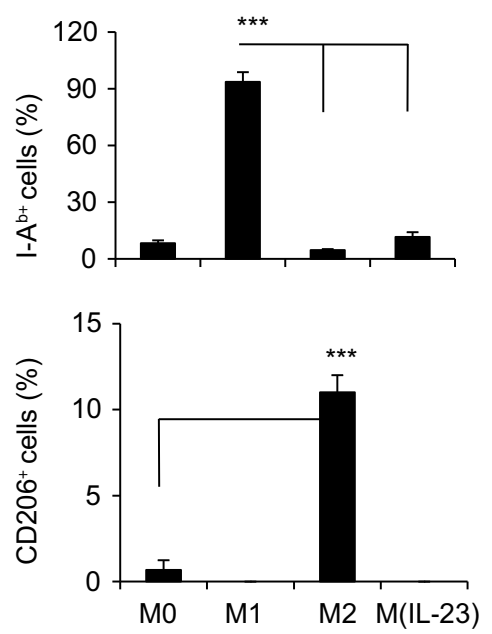

Figure 3. IL-23-treated macrophages display a distinctive gene expression profile. (A) Heatmap diagram summarizing gene expression in M0, M1, M2 and M(IL-23) cells. Relative gene expression was depicted according to the color scale shown below the cluster. (B) Venn diagram of up-regulated (top) and down-regulated (bottom) genes in M1, M2 and M(IL-23) compared with M0 cells. (C) Heatmap diagram summarizing cytokines and chemokines expression in M0, M1, M2 and M(IL-23) macrophages. Relative gene expression was depicted according to the color scale. (D) Representative staining of I-A ${ }^{\mathrm{b}}$, and CD206 on M0, M1, M2 and M(IL-23) cells. (E) Percentages of $\mathrm{I}-\mathrm{A}^{\mathrm{b}+}$, and $\mathrm{CD} 206^{+}$cells in F4/80 $0^{+} \mathrm{M} 0, \mathrm{M} 1$ and M(IL-23) cells. Data were shown as mean $\pm \mathrm{SD}(n=3)$. ${ }^{* * \star} P<0.001$ for comparisons between the indicated groups.

they are likely involved in IL-23-driven M(IL-23) polarization. Consistently, specific inhibition of RORYT by a chemical SR2211 (Kumar et al., 2012) significantly decreased the IL17A, IL-17F and IL-22 but not IFN- $\gamma$ expression in mRNA $(P<0.001$, Fig. S10B $)$ and protein levels $(P<0.001$, Fig. 5F). To further confirm the roles of RORYT in the Th17type cytokines expression in macrophages induced by IL-23, we freshly isolated $\mathrm{CD} 11 \mathrm{~b}^{+} \mathrm{F} 4 / 80^{+}$peritoneal macrophages from RORYT KO and wild-type control mice and then treated these cells with IL-23 in vitro. As shown in Fig. S13, significantly less IL-17A, IL-17F and IL-22 expression but not IFN-Y expression was detected in RORYT-deficient macrophages compared with wild-type control macrophages $(P<0.01$, Fig. S13). As expected, inhibiting STAT3 activity significantly blocked the IL-23-induced RORYT expression in macrophages (Fig. 5E), indicating RORYT is a down-stream molecule in IL-23-activated STAT3 pathway. Thus, IL-23 induces IL-17A, IL-17F and IL-22 expression in macrophages through a STAT3-RORYT-dependent pathway.

To understand the intracellular signal pathway for IFN-Y production in M(IL-23) macrophages, we detected the Th1related key transcription factor T-bet (Robinson and O'Garra, 2002). The expression of T-bet was significantly up-regulated in macrophages after IL-23 treatment as determined by real-time PCR and Western blots (Fig. 5G and 5H). Macrophages isolated from T-bet KO mice expressed significantly lower IFN-y after IL-23 treatment $(P<0.001$, Fig. 5I). However, the T-bet deficiency failed to impact the IL-17A, IL-17F 

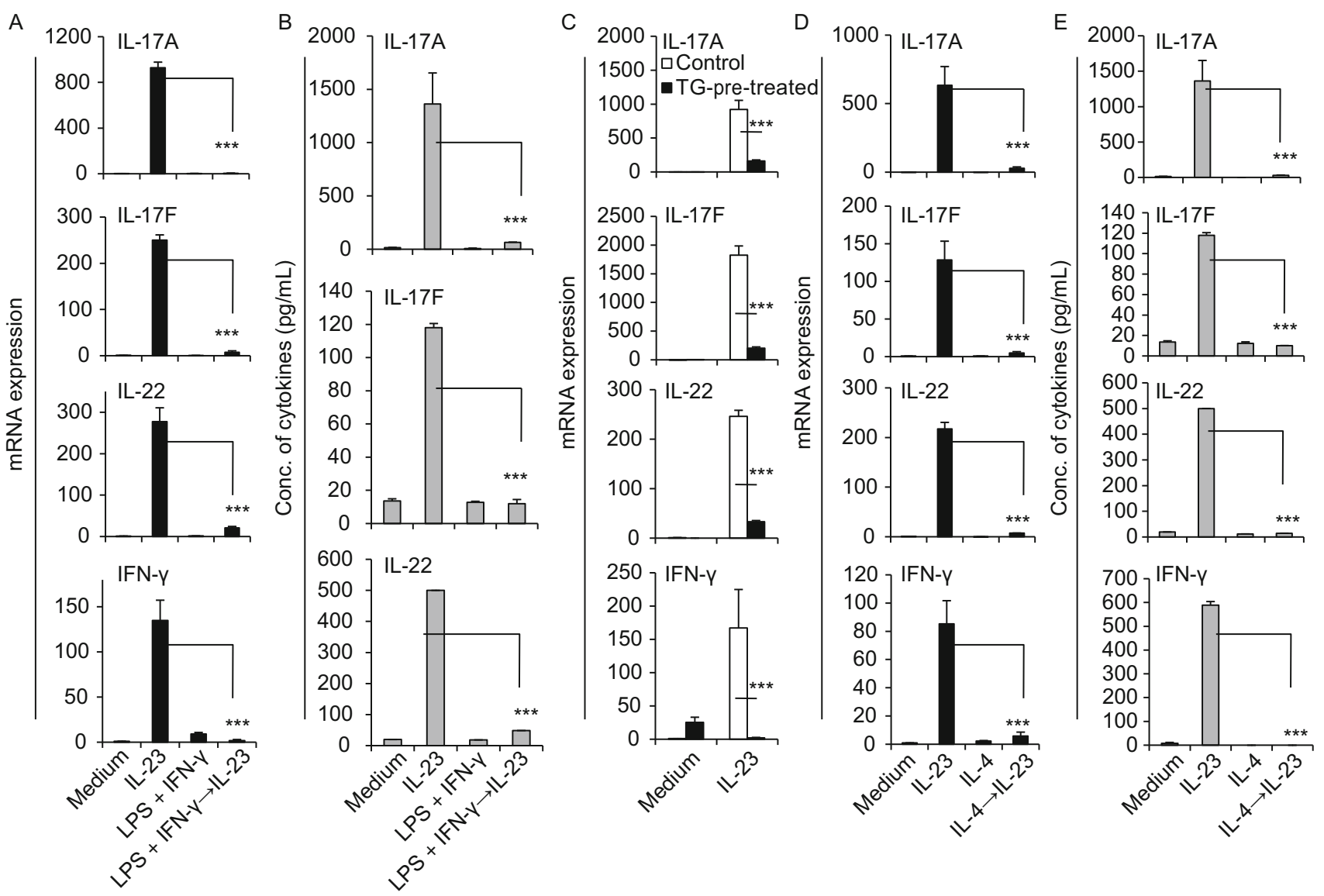

Figure 4. $M(I L-23), M 1$ and $M 2$ polarizations are reciprocally regulated. (A) The mRNA expression of IL-17A, IL-17F, IL-22 and IFN- $y$ in M0, M1, M(IL-23) and IL-23-treated M1 cells. (B) Concentrations of IL-17A, IL-17F and IL-22 cytokines in culture media of M0, M1, M(IL-23) and IL-23-treated M1 cells. (C) mRNA expression of IL-17A, IL-17F, IL-22 and IFN-y in resting and TG-recruited peritoneal macrophages treated with or without IL-23 for $48 \mathrm{~h}$. (D) mRNA expression of IL-17A, IL-17F, IL-22 and IFN-y in M0, M2, M (IL-23) and IL-23-treated M2 cells. (E) Concentrations of IL-17A, IL-17F and IL-22 in the culture media of M0, M2, M(IL-23) and IL-23treated M2 cells. Data were shown as mean $\pm \mathrm{SD}(n=3)$. ${ }^{\star \star} P<0.001$ for comparisons between the indicated groups.

and IL-22 expression in macrophages induced by IL-23 (Fig. S14). These results suggest that the enhanced T-bet in macrophages by IL-23 is involved in the IFN-y but not IL17A, IL-17F and IL-22 expression.

\section{The roles of M(IL-23) macrophages in a psoriasis model}

IL-23 and IL-17 are crucial in the pathogenesis of psoriasis, EAE, CIA, IBD (Cua et al., 2003; Murphy et al., 2003; Wilson et al., 2007; Tonel et al., 2010) and LAD1 (Moutsopoulos et al., 2017). We employed an imiquimod (IMQ)-induced murine model of psoriasis, in which Th17 cytokines like IL-23 and IL-17 were highly involved (van der Fits et al., 2009; Imai et al., 2015). CD11 $\mathrm{b}^{+} \mathrm{F} 4 / 80^{+}$macrophages sorted from skin tissue (Fig. S15) with IMQ-induced psoriasis-like dermatitis expressed high levels of IL-17A and IL-22 molecules (Fig. 6A). In order to investigate whether the induced M(IL23) cells could promote the pathogenesis in the IMQ-induced psoriasis mouse model, we used a suboptimal dose of IMQ (about $35 \mathrm{mg}$ per mouse) to induce a weak psoriasis-like dermatitis. A suboptimal dose of IMQ treatment caused a weak but observable dermatitis, while the treatment with a standard dose of IMQ (about $70 \mathrm{mg}$ per mouse) induced a typical clinical and pathological alteration of psoriasis-like dermatitis as indicated by the body weight loss, scores of skin scaling, erythema, hardness and thickness, as well as skin pathological changes (Fig. 6B-H). Adoptive transfer of IL-23-induced M(IL-23) macrophages into recipient mice with suboptimal IMQ treatment significantly enhanced the severity of dermatitis to a degree caused by the treatment of a high dose of IMQ, as evidenced by the alterations of body weight, skin scaling, erythema, hardness, thickness, and pathological changes, whereas adoptive transfer of resting macrophages failed to do so $(P<0.01$, Fig. $6 \mathrm{~B}-\mathrm{H})$. In parallel to the pathogenesis, the IL-17A, IL-17F, and IL-22 mRNA expression in skin tissues were significantly 
A

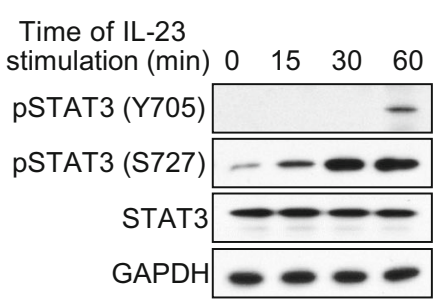

C

Time of IL-23

stimulation (d) $\quad 0 \quad 1 \quad 2 \quad 3$

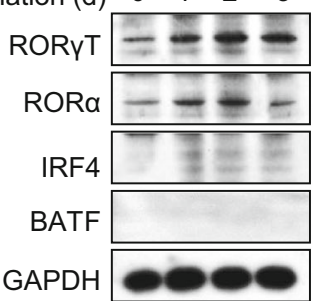

B
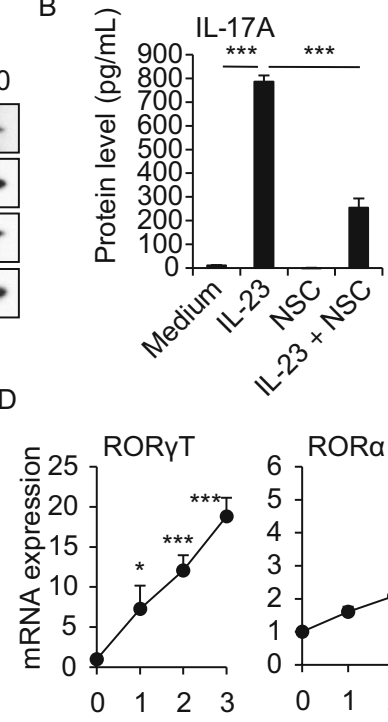

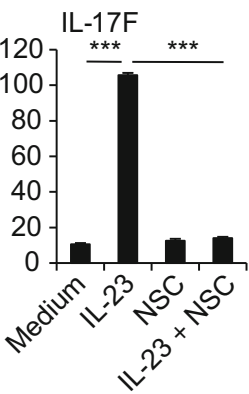

RORa
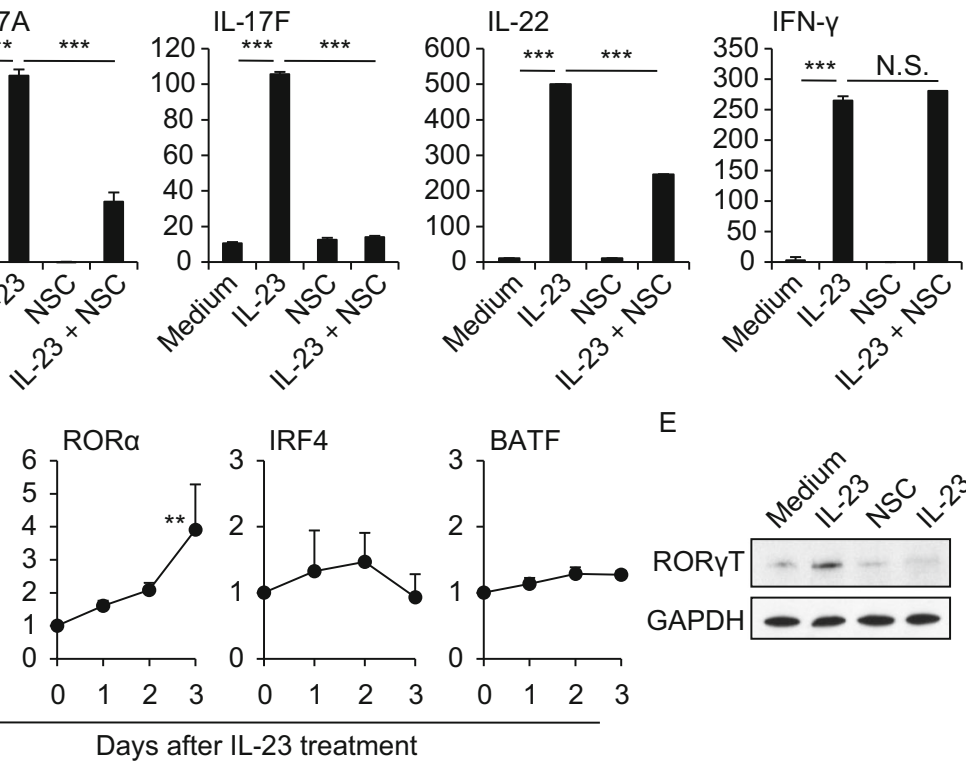

E

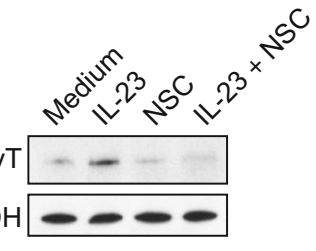

Days after IL-23 treatment
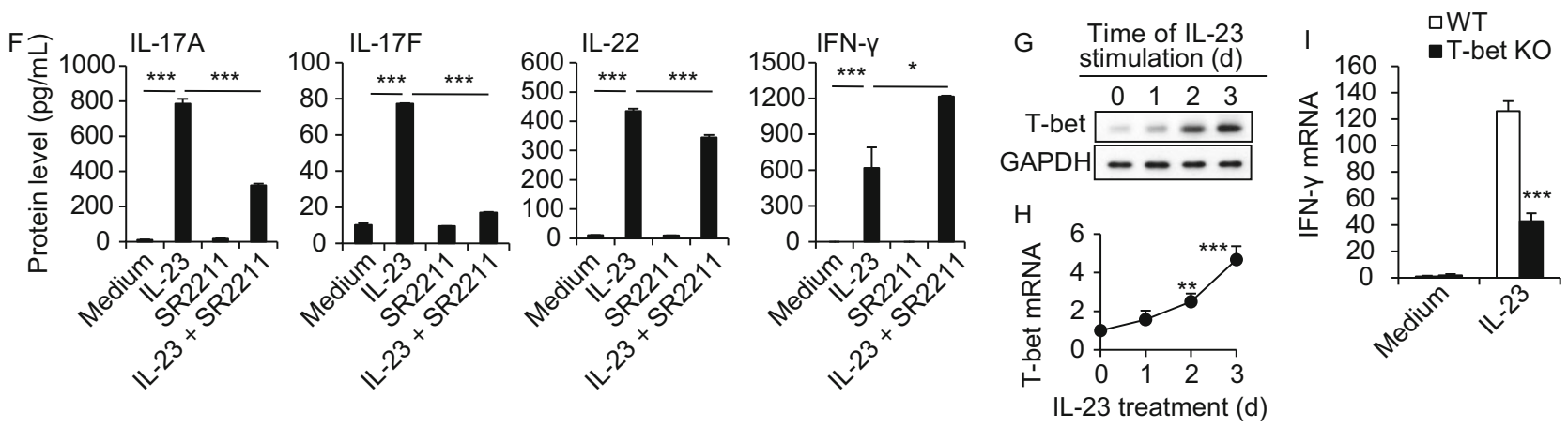

Figure 5. The involvement of STAT3-RORYT and T-bet in M(IL-23) polarization. (A) The phosphorylation state of STAT3 in PEMs. (B) The protein concentrations of IL-17A, IL-17F, IL-22 and IFN-y in culture media of macrophages treated with IL-23 and/or STAT3 inhibitor NSC74859. (C) The expression of RORYT, RORa, IRF4 and BATF in macrophages. (D) The mRNA expression of RORYT, RORa, IRF4 and BATF in macrophages. (E) RORYT expression in macrophages treated with or without IL-23 and/or NSC74859. (F) Protein concentrations of IL-17A, IL-17F, IL-22 and IFN- $y$ in culture media of macrophages. T-bet protein (G) and mRNA $(\mathrm{H})$ expression in macrophages treated with IL-23. (I) The decreased expression of IFN-y in T-bet-deficient macrophages. Data were shown as mean $\pm \mathrm{SD}(n=3) .{ }^{*} P<0.05,{ }^{* * *} P<0.001$.

increased by adoptive transfer of $\mathrm{M}(\mathrm{IL}-23)$ macrophages $(P<0.001$, Fig. $6 \mathrm{I})$. Thus, M(IL-23) macrophages have the ability to promote the pathogenesis in a mouse model with psoriasis-like dermatitis.

\section{DISCUSSION}

Macrophage polarization is determined by genetic and environmental factors. Macrophage polarizations play a critical role in mastering the amplitudes and types of host immunity. In the present study, we identified a previously unappreciated macrophage polarization, that is, M(IL-23) macrophage subpopulation with the following characteristics and supporting evidences: 1) IL-23-treated resting macrophages display distinct gene expression profiling than M1 and M2 macrophages; 2) IL-23-treated resting macrophages selectively produce IL-17A, IL-17F, IL-22 and IFN- $\gamma$, but not M1 and M2-related cytokines and molecules including TNFa, IL-12, iNOS, Arg1, YM1, and FIZZ1; 3) Resting macrophages are susceptible to M(IL-23) induction, while polarized M1 and M2 macrophages are highly resistant to IL-23 treatment. 4) IL-23-treated resting macrophages present in psoriasis-like dermatitis and promote pathogenesis; and 5) IL-23-induced IL-17A, IL-17F and IL-22 expression in macrophages is dependent on STAT3-RORYT pathway, while the expression of IFN- $y$ in IL-23-treated macrophages was likely mediated by T-bet pathway. Therefore, IL-23-treated macrophages display distinct phenotype and cytokine production compared with M1 and M2 macrophages. 

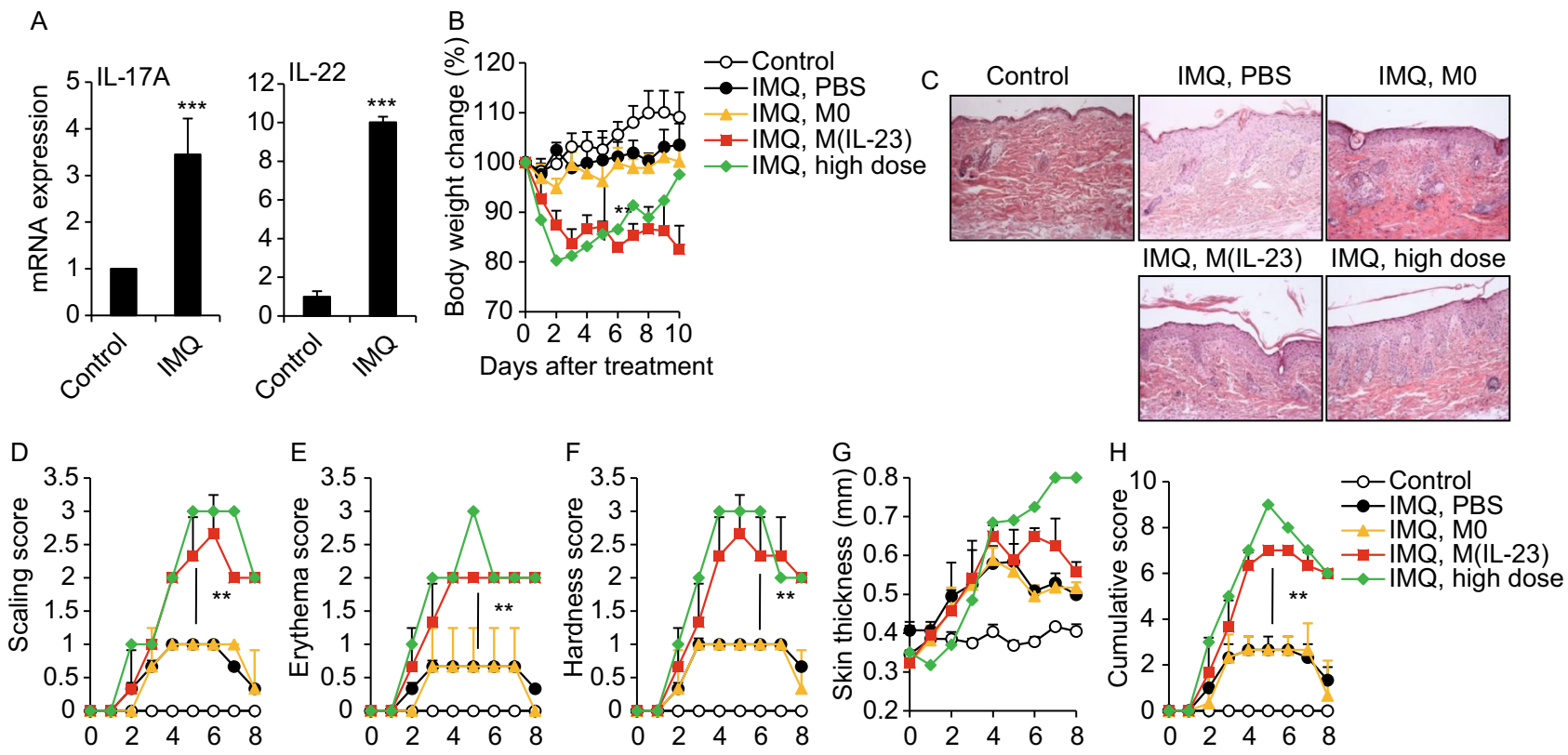

I
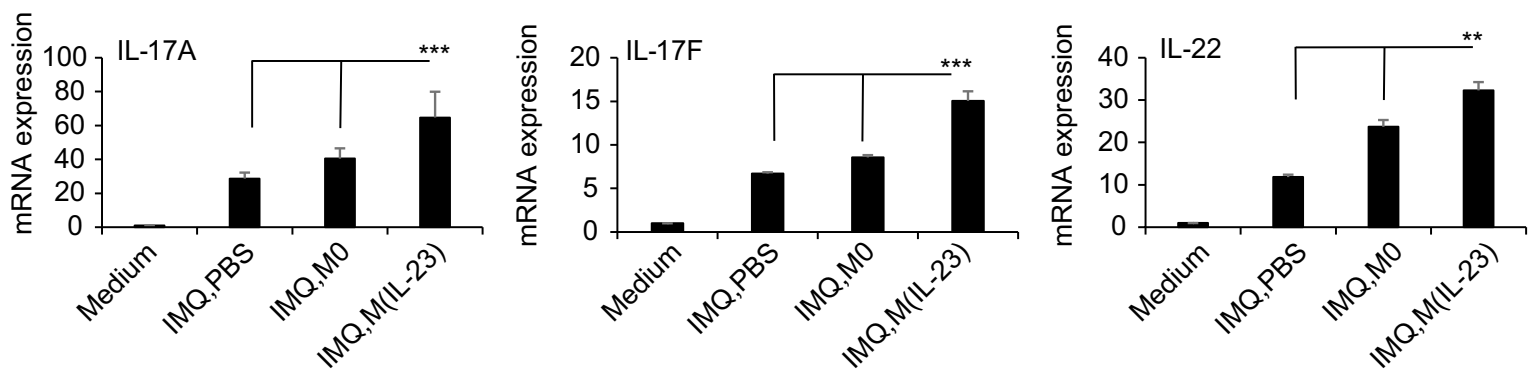

Figure 6. $M(I L-23)$ promoted the pathogenesis in imiquimod-induced psoriasis mice. (A) mRNA expression of IL-17A and IL-22 in the sorted $\mathrm{F} 4 / 80^{+}$macrophages of skin tissue. (B) We used a suboptimal dose of IMQ (35 mg/day), and a standard dose of IMQ (70 $\mathrm{mg} /$ day) was used as a positive control (IMQ, high dose). The IMQ ( $35 \mathrm{mg} /$ day)-treated mice were transferred with $\mathrm{PBS}, 1 \times 10^{6} \mathrm{M0}$ or M(IL-23) macrophages. Body weight loss was shown. (C) H\&E staining of the skin tissues. Scaling score (D), erythema score (E), hardness score $(F)$, skin thickness $(G)$ and cumulative score $(\mathrm{H})$ of mice. (I) mRNA expression of IL-17A, IL-17F, and IL-22 in skin tissues. Data were shown as mean $\pm \operatorname{SD}(n=8) .{ }^{* *} \mathrm{P}<0.01,{ }^{\star * *} P<0.001$ for comparisons between the indicated groups.

It is reported that IL-23 significantly contributes to inflammatory disease risk in humans (Duerr et al., 2006; Genetic Analysis of Psoriasis et al., 2010). Mice deficient in IL-23 but not IL-12 are resistant to experimental immunemediated disease like EAE, RA, and IBD (Cua et al., 2003; Murphy et al., 2003). The promotion of Th17 subset is highly recognized to be the key player to mediate the critical role of IL-23 in inflammatory diseases and infection-induced pathological consequences like Lyme disease and toxoplasma encephalitis (Weaver et al., 2013). Our present study shows that IL-23 acts directly on macrophages to induce IL17A, IL-17F, IL-22 and IFN-y productions which likely promote the severity of psoriasis-like dermatitis in mice. The ability of IL-23 to induce IL-17 production in macrophages is consistent with the recent observations showing that IL-17 production by macrophages contributes to allergic asthma and that IL-23 protection against plasmodium berghei infection in mice is partially dependent on IL-17 from macrophages (Song et al., 2008; Ishida et al., 2013). The significance of $\mathrm{M}(\mathrm{IL}-23)$ macrophage polarization in Th17 cytokines-related inflammatory diseases requires to be clarified.

IL-23, an IL-12 cytokine family member, is a heterodimeric molecule composed of p40 and p19 subunits (Langrish et al., 2005). The known biological roles and the pro-inflammatory activities of IL-23 in inflammation and autoimmune diseases include but not limit to the induction of Th17-induced secretion of IL-17 and suppression of $\mathrm{CD} 4^{+} \mathrm{CD} 25^{+}$regulatory T cells (Iwakura and Ishigame, 2006; Izcue et al., 2008). IL-23 signals through IL-23R and IL-12R $\beta 1$ to activate JAK and predominantly the phosphorylation and activation of STAT3 (Oppmann et al., 2000), which acts to promote transcription of 
II23r and Rorc (encoding RORY), establishing a positive feedback loop and stabilizing expression of genes encoding pro-inflammatory effector molecules including II17a, II17f, II22 and Csf2 (Parham et al., 2002; Codarri et al., 2011). In macrophages, IL-23 uses the classical STAT3-RORYT pathway to induce Th17 cytokines gene expression profile. On the other hand, IFN- $\gamma$ is characteristically produced by NK, T and NKT cells. It is reported that monocytes/macrophages can express IFN-y by IL-12/IL-18 and LPS/ATP stimulations, respectively (Raices et al., 2008). In the present study, LPS + IFN-y and IL4 failed to induce detectable IFN- $y$ expression in resting macrophages, but IL-23 drove resting macrophages to express high levels of IFN-y via T-bet pathway.

In summary, we identified a unique macrophage subpopulation M(IL-23) induced by IL-23 with a distinct gene expression profile in contrast to M1 and M2 macrophages. Importantly, IL23-induced M(IL-23) macrophage polarization is closely involved in the pathogenesis in an IMQ-induced psoriasis mouse model. The physiological function of M(IL-23) macrophages in tissue repair and remodeling, as well as the role of $M$ (IL-23) macrophages in pathogenesis caused by infections, tumors and graft rejection need to be explored in the future.

\section{MATERIALS AND METHODS}

Animals and reagents

C57BL/6(B6) mice were purchased from Beijing University Experimental Animal Center. ROR-yt knock-out (KO) mice (B6.129P2(Cg)-

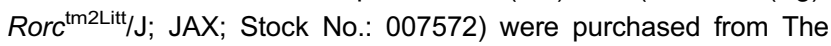
Jackson Laboratory. All mice were maintained in a specific pathogen-free facility. All experimental manipulations were undertaken in accordance with the Institutional Guidelines for the Care and Use of Laboratory Animals, Institute of Zoology.

Recombinant mouse cytokines were purchased from PeproTech (Rocky Hill, NJ). RmIL-21 and IL-23 were obtained from R\&D Systems (Minneapolis, MN). Bacterial lipopolysaccharide (LPS; E. coli 055:B5) was purchased from Sigma-Aldric (St Louis, MO). Selective STAT3 inhibitor (NSC74859; 4655/10) were obtained from R\&D Systems and RORYT inverse agonist (SR2211; 557353) were from The Merck Group (Darmstadt, Germany). The reagents were used at the indicated or following concentrations based on our previous studies (Hou et al., 2013; Hou et al., 2014): recombinant mouse IL$1 \beta(100 \mathrm{ng} / \mathrm{mL}), \mathrm{IL}-2(100 \mathrm{U} / \mathrm{mL}), \mathrm{IL}-4(1000 \mathrm{U} / \mathrm{mL}), \mathrm{IL}-6(20 \mathrm{ng} / \mathrm{mL})$, IL-10 (20 ng/mL), IL-12 (10 ng/mL), IL-13 (20 ng/mL), IL-17A (100 $\mathrm{ng} / \mathrm{mL}), \mathrm{IL}-21(100 \mathrm{ng} / \mathrm{mL}), \mathrm{IL}-23(100 \mathrm{ng} / \mathrm{mL}), \mathrm{IL}-33(100 \mathrm{ng} / \mathrm{mL})$, TNF- $\alpha$ (100 ng/mL), IFN- $\gamma(50 \mathrm{ng} / \mathrm{mL})$ TGF- $\beta 1(5 \mathrm{ng} / \mathrm{mL})$; and recombinant human IL-23 (100 $\mathrm{ng} / \mathrm{mL})$, M-CSF (10 ng/mL); LPS

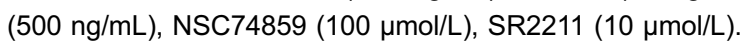

Anti-mF4/80-PE-Cy5, anti-mCD11b-PE-Cy5, anti-mTNF-a-FITC and anti-mCXCR5-PE were purchased from BD Biosciences Pharmingen (San Diego, CA, US). Anti-mIL-17A-PE was purchased from Biolegend (San Diego, CA, US). Anti-mIL-23R-AF488 mAb was purchased from R\&D Systems. The primary antibodies against p-STAT3 (Tyr705), p-STAT3 (Ser727), STAT3, IRF4 and BATF were purchased from Cell Signaling Technology (Beverly, MA, US). The primary antibodies against RORYT were from Millipore Biotechnology (Billerica, MA, US).

\section{Cell isolation}

Primary mouse peritoneal macrophages were obtained from B6 mice as described previously (Zhu et al., 2014). The purity of macrophages was more than $90 \%$ of $\mathrm{CD}_{11} \mathrm{~b}^{+} \mathrm{F} 4 / 80^{+}$macrophages as analyzed by flow cytometry (Yang et al., 2016). For real-time PCR and ELISA assays, $\mathrm{CD} 11 \mathrm{~b}^{+} \mathrm{F} 4 / 80^{+}$macrophages were further sorted by a MoFlo XDP High Speed Cell Sorter (Beckman Coulter).

\section{Microarray hybridization and data analysis}

Total RNA was amplified and labeled by Low Input Quick Amp Labeling Kit, One-Color (Cat\#5190-2305, Agilent technologies, Santa Clara, CA, US). Differentially expressed genes were defined as genes with at least 2 fold variance of expression levels in M1, M2 and $\mathrm{M}(\mathrm{IL}-23)$ polarized macrophages compared to $\mathrm{M0}$ macrophages.

\section{Immunofluorescent staining}

Cells were cultured on coverslips for the indicated time and then fixed in $4 \%$ paraformaldehyde for $10 \mathrm{~min}$ and stored in PBS at $4{ }^{\circ} \mathrm{C}$ (Hou et al., 2014). Cells were permeabilized and blocked and then were incubated with the indicated mAbs (1:100 dilution) overnight at $4^{\circ} \mathrm{C}$. Following PBS washes, the secondary Ab was applied for $1 \mathrm{~h}$ and HOECHST33342 $(2 \mu \mathrm{g} / \mathrm{mL})$ for $10 \mathrm{~min}$. Photomicrographs were taken using an LSM510META Laser Scanning Microscope (Zeiss, Germany).

\section{Western blot}

It was performed as described (Sun et al., 2012). Protein bands were visualized by adding HRP membrane substrate (Millipore) and then scanned using the Tanon 1600R Gel Image System (Tanon Co., Ltd., Shanghai, China). GAPDH mAb (Proteintech Group, Inc) was used to normalize for the amount of loaded protein.

\section{ELISA}

IL-17A, IL-17F, IL-22 and IFN-y ELISA assays were performed following the manufacturer's instructions (Biolegend).

\section{Quantitative PCR}

Real-time PCR was performed using multiple kits (SYBR Premix Ex TaqTM, DRR041A, Takara Bio) on CFX96 (Bio-Rad) (Li et al., 2017). The primers are listed in Table S1. Housekeeping gene hypoxanthine phosphoribosyl transferase (HPRT) was used as an internal control.

\section{IMQ-induced psoriasis}

The day that psoriasis was first induced by imiquimod (IMQ) was defined as day 0 . On days -1 and $1, B 6$ mice were injected i.v. with $1 \times 10^{6} \mathrm{IL}-23$-induced macrophages which were treated with IL-23 for $72 \mathrm{~h}$ in vitro as described above. B6 mice were used to induce psoriasis by IMQ as described previously (van der Fits et al., 2009). Mice were evaluated daily. Back redness (erythema), presence of scales (scaling), and hardness of the skin were scored using a semiquantitative scoring system from 0 to 4 based on their external 
physical appearance: $0=$ no skin abnormalities, $1=$ slight, $2=$ moderate, $3=$ marked, and $4=$ severe. In addition, mice were weighed, and dorsal skin thickening was assessed by measuring double-skin fold thickness using a digital micrometer (Mitutoyo). At the end of the experiment, back skin samples were fixed in $4 \%$ formaldehyde and stained with H\&E. Parakeratosis, acanthosis and leukocyte infiltration were assessed to evaluate scores in a blinded way. Scores from 0 to 2 were given, as follows: $0=$ no abnormalities; 1 = psoriasis-like dermatitis: epidermal acanthosis, reduction of granulose layer, and hyperkeratosis with modest leukocyte infiltration; 2 = psoriasis-like dermatitis: higher epidermal acanthosis, absence of granulose layer, and higher hyperkeratosis with leukocyte infiltration enriched in neutrophils.

\section{Intracellular cytokine staining}

Macrophages were treated with GolgiPlug (BD Pharmingen) for the last $6 \mathrm{~h}$ of incubation (Zhu et al., 2014). Cells were fixed and permeabilized with fixation and permeabilization solution (BD; 553722) and Perm/Wash buffer (BD; 554723). Cells were analyzed for the intracellular production of cytokines by staining with anti-mTNF-aFITC, anti-mIFN- $\gamma-P E$, or anti-mIL-17A-PE, respectively. The cells were then detected by a flow cytometry.

\section{Statistical analysis}

Data are presented as mean $\pm \mathrm{SD}$. Student's unpaired $t$ test for comparison of means was used. For multiple group comparison, significant difference was calculated using the non-parametric Mann-Whitney $U$ test. A $P$ value less than 0.05 was considered significant.

\section{ACKNOWLEDGEMENTS}

The authors thank Dr. Lianjun Zhang for his reading the manuscript, Mrs. Qing Meng, Mrs. Xiaoqiu Liu, and Mr. Yabing Liu for their expert technical assistance, Mrs. Ling Li for her excellent laboratory management. This work was supported by grants from the National Natural Science Foundation for General and Key Programs (C81530049, C81130055, C31470860, Y.Z.), Knowledge Innovation Program of Chinese Academy of Sciences (XDA04020202-19, Y.Z.), and the CAS/SAFEA International Partnership Program for Creative Research Teams (Y.Z.).

\section{ABBREVIATIONS}

CIA, collagen-induced arthritis; DCs, dendritic cells; EAE, experimental autoimmune encephalomyelitis; IBD, inflammatory bowel disease; ILCs, innate lymphoid cells; IMQ, imiquimod; LAD1, leukocyte adhesion deficiency type 1; NK, natural killer; RORYT, retinoid related orphan receptor- $\mathrm{Y}$ T; STAT3, signal transducer and activator of transcription 3 .

\section{COMPLIANCE WITH ETHICS GUIDELINES}

Yuzhu Hou, Linnan Zhu, Hongling Tian, Hai-Xi Sun, Ruoyu Wang, Lianfeng Zhang, and Yong Zhao declare that they have no conflict of interest.
All procedures followed were in accordance with the ethical standards of the responsible committee on human experimentation (institutional and national) and with the Helsinki Declaration of 1975, as revised in 2000 (5). Informed consent was obtained from all patients for being included in the study. All institutional and national guidelines for the care and use of laboratory animals were followed.

\section{AUTHOR CONTRIBUTIONS}

Yuzhu Hou, Linnan Zhu and Hongling Tian designed and carried out the major experiments, and analyzed data; Hai-Xi Sun performed bioinformatics assays. Ruoyu Wang provided experimental supervision and analyzed data; Linnan Zhu provided animal models and revised manuscript; and Yong Zhao designed experiments, analyzed data, wrote manuscript and provided overall supervision.

\section{OPEN ACCESS}

This article is distributed under the terms of the Creative Commons Attribution 4.0 International License (http://creativecommons.org/ licenses/by/4.0/), which permits unrestricted use, distribution, and reproduction in any medium, provided you give appropriate credit to the original author(s) and the source, provide a link to the Creative Commons license, and indicate if changes were made.

\section{REFERENCES}

Awasthi A, Riol-Blanco L, Jager A, Korn T, Pot C, Galileos G, Bettelli E, Kuchroo VK, Oukka M (2009) Cutting edge: IL-23 receptor gfp reporter mice reveal distinct populations of IL-17-producing cells. J Immunol 182:5904-5908

Aychek T, Mildner A, Yona S, Kim KW, Lampl N, Reich-Zeliger S, Boon L, Yogev N, Waisman A, Cua DJ et al (2015) IL-23mediated mononuclear phagocyte crosstalk protects mice from Citrobacter rodentium-induced colon immunopathology. Nat Commun 6:6525

Cella M, Fuchs A, Vermi W, Facchetti F, Otero K, Lennerz JK, Doherty JM, Mills JC, Colonna M (2009) A human natural killer cell subset provides an innate source of IL-22 for mucosal immunity. Nature 457:722-725

Cho ML, Kang JW, Moon YM, Nam HJ, Jhun JY, Heo SB, Jin HT, Min SY, Ju JH, Park KS et al (2006) STAT3 and NF-kappaB signal pathway is required for IL-23-mediated IL-17 production in spontaneous arthritis animal model IL-1 receptor antagonistdeficient mice. J Immunol 176:5652-5661

Chung Y, Chang SH, Martinez GJ, Yang XO, Nurieva R, Kang HS, Ma L, Watowich SS, Jetten AM, Tian Q et al (2009) Critical regulation of early Th17 cell differentiation by interleukin-1 signaling. Immunity 30:576-587

Ciofani M, Madar A, Galan C, Sellars M, Mace K, Pauli F, Agarwal A, Huang W, Parkurst CN, Muratet M et al (2012) A validated regulatory network for Th17 cell specification. Cell 151:289-303

Codarri L, Gyulveszi G, Tosevski V, Hesske L, Fontana A, Magnenat L, Suter T, Becher B (2011) RORgammat drives production of the cytokine GM-CSF in helper T cells, which is essential for the 
effector phase of autoimmune neuroinflammation. Nat Immunol 12:560-567

Cua DJ, Sherlock J, Chen Y, Murphy CA, Joyce B, Seymour B, Lucian L, To W, Kwan S, Churakova T et al (2003) Interleukin-23 rather than interleukin-12 is the critical cytokine for autoimmune inflammation of the brain. Nature 421:744-748

Duerr RH, Taylor KD, Brant SR, Rioux JD, Silverberg MS, Daly MJ, Steinhart AH, Abraham C, Regueiro M, Griffiths A et al (2006) A genome-wide association study identifies IL23R as an inflammatory bowel disease gene. Science 314:1461-1463

Genetic Analysis of Psoriasis C, the Wellcome Trust Case Control C, Strange A, Capon F, Spencer CC, Knight J, Weale ME, Allen MH, Barton A, Band G et al (2010). A genome-wide association study identifies new psoriasis susceptibility loci and an interaction between HLA-C and ERAP1. Nat Genet 42:985-990.

Guo L, Junttila IS, Paul WE (2012) Cytokine-induced cytokine production by conventional and innate lymphoid cells. Trends Immunol 33:598-606

Hou Y, Lin H, Zhu L, Liu Z, Hu F, Shi J, Yang T, Shi X, Zhu M, Godley BF et al (2013) Lipopolysaccharide increases the incidence of collagen-induced arthritis in mice through induction of protease HTRA-1 expression. Arthritis Rheum 65:2835-2846

Hou Y, Lin H, Zhu L, Liu Z, Hu F, Shi J, Yang T, Shi X, Guo H, Tan X et al (2014) The inhibitory effect of IFN-gamma on protease HTRA1 expression in rheumatoid arthritis. J Immunol 193:130138

Huber M, Brustle A, Reinhard K, Guralnik A, Walter G, Mahiny A, von Low E, Lohoff M (2008) IRF4 is essential for IL-21-mediated induction, amplification, and stabilization of the Th17 phenotype. Proc Natl Acad Sci U S A 105:20846-20851

Imai Y, Ayithan N, Wu X, Yuan Y, Wang L, Hwang ST (2015) Cutting Edge: PD-1 Regulates Imiquimod-Induced Psoriasiform Dermatitis through Inhibition of IL-17A Expression by Innate gammadeltaLow T Cells. J Immunol 195:421-425

Ishida H, Imai T, Suzue K, Hirai M, Taniguchi T, Yoshimura A, Iwakura Y, Okada H, Suzuki T, Shimokawa C et al (2013) IL-23 protection against Plasmodium berghei infection in mice is partially dependent on IL-17 from macrophages. Eur J Immunol 43:2696-2706

Iwakura Y, Ishigame H (2006) The IL-23/IL-17 axis in inflammation. J Clin Invest 116:1218-1222

Izcue A, Hue S, Buonocore S, Arancibia-Carcamo CV, Ahern PP, Iwakura Y, Maloy KJ, Powrie F (2008) Interleukin-23 restrains regulatory $\mathrm{T}$ cell activity to drive $\mathrm{T}$ cell-dependent colitis. Immunity 28:559-570

Kadi A, Costantino F, Izac B, Leboime A, Said-Nahal R, Garchon HJ, Chiocchia G, Breban M (2013) Brief Report: The IL23R Nonsynonymous Polymorphism rs11209026 is Associated With Radiographic Sacroiliitis in Spondyloarthritis. Arthritis Rheum 65:26552660

Kastelein RA, Hunter CA, Cua DJ (2007) Discovery and biology of IL-23 and IL-27: related but functionally distinct regulators of inflammation. Annu Rev Immunol 25:221-242

Kumar N, Lyda B, Chang MR, Lauer JL, Solt LA, Burris TP, Kamenecka TM, Griffin PR (2012) Identification of SR2211: a potent synthetic RORgamma-selective modulator. ACS Chem Biol 7:672-677
Labonte AC, Tosello-Trampont AC, Hahn YS (2014) The role of macrophage polarization in infectious and inflammatory diseases. Mol Cells 37:275-285

Langrish CL, Chen Y, Blumenschein WM, Mattson J, Basham B, Sedgwick JD, McClanahan T, Kastelein RA, Cua DJ (2005) IL-23 drives a pathogenic $T$ cell population that induces autoimmune inflammation. J Exp Med 201:233-240

Li Y, Zhu L, Chu Z, Yang T, Sun HX, Yang F, Wang W, Hou Y, Wang $P$, Zhao $Q$ et al (2017) Characterization and biological significance of IL-23-induced neutrophil polarization. Cell Mol Immunol 14:1-13

Lubberts E (2015) The IL-23-IL-17 axis in inflammatory arthritis. Nat Rev Rheumatol 11:415-429

McGeachy MJ, Chen Y, Tato CM, Laurence A, Joyce-Shaikh B, Blumenschein WM, McClanahan TK, O'Shea JJ, Cua DJ (2009) The interleukin 23 receptor is essential for the terminal differentiation of interleukin 17-producing effector T helper cells in vivo. Nat Immunol 10:314-324

Moutsopoulos NM, Zerbe CS, Wild T, Dutzan N, Brenchley L, DiPasquale G, Uzel G, Axelrod KC, Lisco A, Notarangelo LD et al (2017) Interleukin-12 and Interleukin-23 Blockade in Leukocyte adhesion deficiency type 1. N Engl J Med 376:1141-1146

Murphy CA, Langrish CL, Chen Y, Blumenschein W, McClanahan T, Kastelein RA, Sedgwick JD, Cua DJ (2003) Divergent pro- and antiinflammatory roles for IL-23 and IL-12 in joint autoimmune inflammation. J Exp Med 198:1951-1957

Murray PJ, Wynn TA (2011) Protective and pathogenic functions of macrophage subsets. Nat Rev Immunol 11:723-737

Oppmann B, Lesley R, Blom B, Timans JC, Xu Y, Hunte B, Vega F, Yu N, Wang J, Singh K et al (2000) Novel p19 protein engages IL$12 \mathrm{p} 40$ to form a cytokine, IL-23, with biological activities similar as well as distinct from IL-12. Immunity 13:715-725

Paget C, Ivanov S, Fontaine J, Renneson J, Blanc F, Pichavant M, Dumoutier L, Ryffel B, Renauld JC, Gosset P et al (2012) Interleukin-22 is produced by invariant natural killer T lymphocytes during influenza A virus infection: potential role in protection against lung epithelial damages. J Biol Chem 287:8816-8829

Parham C, Chirica M, Timans J, Vaisberg E, Travis M, Cheung J, Pflanz S, Zhang R, Singh KP, Vega $F$ et al (2002) A receptor for the heterodimeric cytokine IL-23 is composed of IL-12Rbeta1 and a novel cytokine receptor subunit, IL-23R. J Immunol 168:56995708

Park H, Li Z, Yang XO, Chang SH, Nurieva R, Wang YH, Wang Y, Hood L, Zhu Z, Tian Q et al (2005) A distinct lineage of CD4 T cells regulates tissue inflammation by producing interleukin 17 . Nat Immunol 6:1133-1141

Raices RM, Kannan Y, Sarkar A, Bellamkonda-Athmaram V, Wewers MD (2008) A synergistic role for IL-1beta and TNFalpha in monocyte-derived IFNgamma inducing activity. Cytokine 44:234-241

Remmers EF, Cosan F, Kirino Y, Ombrello MJ, Abaci N, Satorius C, Le JM, Yang B, Korman BD, Cakiris A et al (2010) Genome-wide association study identifies variants in the MHC class I, IL10, and IL23R-IL12RB2 regions associated with Behcet's disease. Nat Genet 42:698-702

Robinson DS, O'Garra A (2002) Further checkpoints in Th1 development. Immunity 16:755-758 
Song C, Luo L, Lei Z, Li B, Liang Z, Liu G, Li D, Zhang G, Huang B, Feng ZH (2008) IL-17-producing alveolar macrophages mediate allergic lung inflammation related to asthma. J Immunol 181:6117-6124

Sun C, Sun L, Ma H, Peng J, Zhen Y, Duan K, Liu G, Ding W, Zhao Y (2012) The phenotype and functional alterations of macrophages in mice with hyperglycemia for long term. J Cell Physiol 227:1670-1679

Teng MW, Bowman EP, McElwee JJ, Smyth MJ, Casanova JL, Cooper AM, Cua DJ (2015) IL-12 and IL-23 cytokines: from discovery to targeted therapies for immune-mediated inflammatory diseases. Nat Med 21:719-729

Tonel G, Conrad C, Laggner U, Di Meglio P, Grys K, McClanahan TK, Blumenschein WM, Qin JZ, Xin H, Oldham E et al (2010) Cutting edge: A critical functional role for IL-23 in psoriasis. $\mathrm{J}$ Immunol 185:5688-5691

van der Fits L, Mourits S, Voerman JS, Kant M, Boon L, Laman JD, Cornelissen F, Mus AM, Florencia E, Prens EP et al (2009) Imiquimod-induced psoriasis-like skin inflammation in mice is mediated via the IL-23/IL-17 axis. J Immunol 182:5836-5845
Weaver CT, Elson CO, Fouser LA, Kolls JK (2013) The Th17 pathway and inflammatory diseases of the intestines, lungs, and skin. Annu Rev Pathol 8:477-512

Wilson NJ, Boniface K, Chan JR, McKenzie BS, Blumenschein WM, Mattson JD, Basham B, Smith K, Chen T, Morel F et al (2007) Development, cytokine profile and function of human interleukin 17-producing helper T cells. Nat Immunol 8:950-957

Xue J, Schmidt SV, Sander J, Draffehn A, Krebs W, Quester I, De Nardo D, Gohel TD, Emde M, Schmidleithner L et al (2014) Transcriptome-based network analysis reveals a spectrum model of human macrophage activation. Immunity 40:274-288

Yang T, Zhu L, Zhai Y, Zhao Q, Peng J, Zhang $\mathrm{H}$, Yang Z, Zhang L, Ding W, Zhao $Y$ (2016) TSC1 controls IL-1beta expression in macrophages via mTORC1-dependent C/EBPbeta pathway. Cell Mol Immunol 13:640-650

Zhu L, Yang T, Li L, Sun L, Hou Y, Hu X, Zhang L, Tian H, Zhao Q, Peng $J$ et al (2014) TSC1 controls macrophage polarization to prevent inflammatory disease. Nat Commun 5:4696 